\section{$006-007$ \\ Noticias y comentarios \\ PH46 - Diciembre 2003}

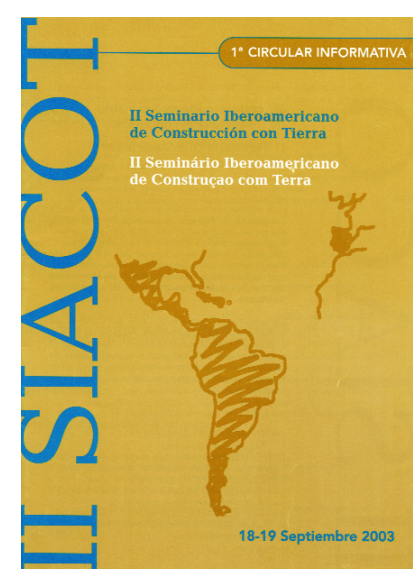

documentación que realiza en España, tanto en el medio universitario como a través de los planes nacionales de I+D.

La II Asamblea General del Proyecto PROTERRA se ha celebrado en Boceguillas (Segovia) los dias 15,16 y 17 de septiembre de 2003 y ha contado con la participación de profesores e investigadores procedentes de Argentina, Bolivia, Brasil, Chile, Colombia, Cuba, Ecuador, El Salvador, España, Honduras, Paraguay, Perú, Portugal, Uruguay y Venezuela. Han patrocinado este encuentro el Ilmo. Ayuntamiento de Boceguillas (Segovia), el Colegio Oficial de Arquitectos de Castilla y León Este (Demarcación de Segovia), la Escuela Técnica Superior de Arquitectura de Madrid, el Programa Iberoamericano de Ciencia y Tecnología para el Desarrollo (CYTED) y la Universidad Politécnica de Madrid.

Esta asamblea ha permitido la discusión de los proyectos que PROTERRA tiene en marcha en estos momentos, así como la creación de comisiones de trabajo sobre distintos aspectos concernientes a la arquitectura y construcción con tierra en Hispanoamérica: elaboración de una instrucción sobre edificación en tierra, recopilación de normativa, cuestiones de terminología, criterios de conservación y restauración del patrimonio arquitectónico de tierra, programas de desarrollo sostenible, construcción de viviendas sociales y autoconstrucción.

\section{El II Seminario Iberoamericano de Construcción con Tierra}

El seminario, que ha contado con la participación de investigadores europeos y americanos, ha reunido en la Escuela Técnica Superior de Arquitectura de Madrid a los principales especialistas en arquitectura y construcción con tierra, entre los que puede destacarse al profesor Gernot Minke, catedrático y director del prestigioso Instituto de
Investigación de Construcciones Experimentales de la Universidad de Kassel (Alemania) o al profesor Hubert Guillaud, catedrático de la Escuela de Arquitectura de Grenoble (Francia) y responsable del Laboratorio CRAterre. Han asistido igualmente a las sesiones científicas de este seminario profesores de distintas escuelas de arquitectura y centros universitarios españoles e hispanoamericanos así como de Portugal, Canadá, Estados Unidos, Gran Bretaña, Alemania o Francia.

Durante dos dias han podido presentarse cerca de medio centenar de ponencias y comunicaciones organizadas en cuatro sesiones: 1) la construcción con tierra actual y la vivienda social; 2) aspectos de diseño y proyecto; 3) aspectos técnico-constructivos e innovación tecnológica, y 4) restauración del patrimonio arquitectónico de tierra, aspectos históricos y documentación. El comité científico del seminario ha estado integrado por los profesores Luis Maldonado Ramos (ETSAM), Célia Neves (UFBA), Julián Salas Serrano (CSIC), David Rivera Gámez (UAX), Fernando Vela Cossío (ETSAM) y Luis de Villanueva Dominguez (ETSAM).

El Centro de Investigación de Arquitectura Tradicional (CIAT) fue creado mediante un convenio suscrito en 1996 entre la Universidad Politécnica de Madrid y el Ayuntamiento de Boceguillas (Segovia), y se encuentra abierto al público en esta localidad segoviana, en la que lleva a cabo distintas actividades de formación, investigación y difusión de la arquitectura tradicional.

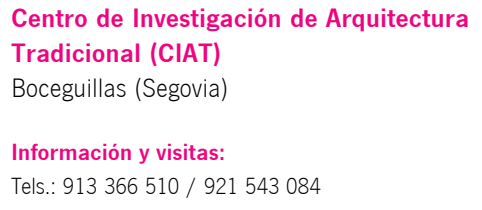

\title{
España acoge a más de 700 participantes en el XIII Congreso Internacional de Numismática
}

Para la investigación numismática, los Congresos Internacionales representan el foro más importante de encuentro, no sólo por su trayectoria y tradición -se crearon en 1891-, sino también por su continuidad, pues se han ido celebrando, sin grandes excepciones, cada seis años.

En Madrid, del 15 al 19 de septiembre, se ha celebrado, por primera vez en un país hispanohablante, el XIII Congreso Internacional de Numismática. El éxito de participación, con 767 participantes procedentes de 54 paises, ha hecho de este encuentro un foro excepcional para compartir las más recientes investigaciones en numismática. El Museo Arqueológico
Nacional se ha ocupado de la coordinación del C.I.N., organizado por el Ministerio de Educación, Cultura y Deporte.

Parte de esta numerosa asistencia ha sido favorecida por las becas que han otorgado distintas instituciones, entre ellas la Comisión Internacional de Numismática, la Dirección General de Cooperación y Comunicación Cultural del Ministerio de Educación, Cultura y Deporte, la Numismatische Kommission der Länder in der Bundesrepublik Deutschland y la Deutsche Numismatische Gesellschaft/Verband der Deutschen Münzvereine.

El Programa previsto se llevó a cabo con escasas modificaciones. Las sesiones de trabajo se desarro- 


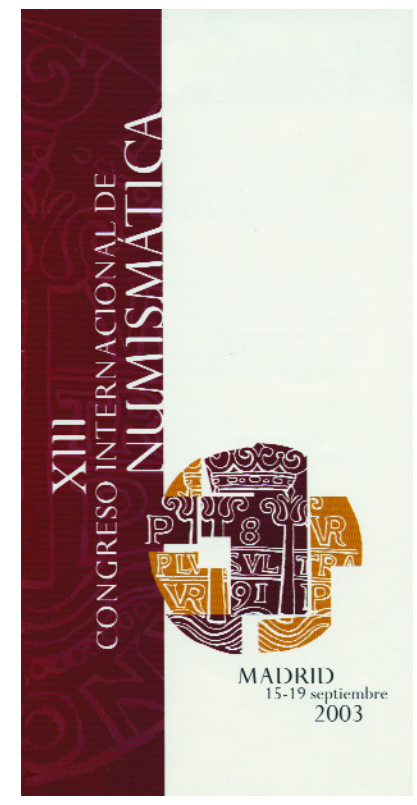

Ilaron en 10 salas con un total de 378 intervenciones que se han repartido en 7 conferencias plenarias, tres mesas redondas, 63 sesiones de comunicaciones y 27 pósters, en los cinco idiomas oficiales del Congreso: español, inglés, francés, italiano y alemán.

Las siete sesiones plenarias y las tres mesas redondas se realizaron en el Auditorio del Palacio de Congreso con traducción simultánea en tres idiomas: español, inglés y francés. La conferencia de inauguración corrió a cargo de Marina Chinchilla Gómez, Subdirectora General de Museos Estatales, con el título La Numismática en los Museos de titularidad y gestión estatal de España. Refiriéndose a la Antigüedad, Pere Pau Ripollès Alegre disertó sobre Las acuñaciones de la península ibérica: dependencias e innovaciones; Andrea Saccocci con La monetazione del Regnum Italiae e l'evoluzione complessiva del sistema monetario Europeo tra VIII e XII secolo explicó el estado de los sistemas monetarios durante la Edad Media; la sesión referente a Edad Moderna y Contemporánea la realizó Benedikt Zäch con Images of the Euro: National representation and European identity; de Numismática Oriental se ocupó en Mining and Minting in the Islamic World and Elsewhere Michael Bates; de Medallas, Marian Scharloo con Golden gifts from the Dutch Republic. The ambassador's medals; y la conferencia de clausura corrió a cargo de Guillermo Céspedes del Castillo, de la Real Academia de la Historia, bajo el título El peso o real de a ocho americano como moneda universal. Las tres mesas redondas se desarrollaron con los siguientes titulos: The future of web databases for numismatic study; Moneda y Ejército: el ejemplo de los Julio-Claudios en Occidente; New researches concerning the authenticity of coins.

Paralelamente, se realizaron otros actos, como la concesión de los premios de la Asociación Internacional de Numismáticos Profesionales y la presentación de diversos libros: Monete, mercanti e matematica. Le monete medievali nei trattati di aritmetica e nei libri di mercatura de Lucia Travaini; II Libro del Pellegrino (Siena,
1382-1446). Affari, uomini, monete nell'ospedale di Santa Maria della Scala de Gabriella Piccinni y Lucia Travaini; La peseta y el Arte. Imágenes en billetes anteriores al euro de Fernando García de Cortázar, Paloma de Roda Lamsfus y Teresa Tortella; y Arma et Nummi. Forschungen zur römischen Finanzgeschichte und Münzprägung der Jahre 49 bis 42 v. Chr. de Bernhard Woytek.

Por otro lado, el día 14 de septiembre, antes de la inauguración del Congreso, se llevaron a cabo tres importantes reuniones: la del Bureau de la Comisión Internacional de Numismática, la Asamblea General de ICOMON y la Asamblea plenaria de la Comisión Internacional de Numismática, en la que, entre otras cuestiones, se elegió la próxima sede del Congreso Internacional de Numismática: Glasgow 2009/2010.

\begin{abstract}
Survey of Numismatic Research
Coincidiendo con cada Congreso Internacional de Numismática se lleva a cabo una recopilación bibliográfica, comentada por especialistas en cada materia, de las publicaciones de Numismática aparecidas en los seis años transcurridos entre uno y otro encuentro. El Survey que se ha editado para este Congreso se estructura en capitulos temáticos sobre Antigüedad, Edades Media, Moderna y Contemporánea, Numismática Oriental, Medallas y Numismática General.
\end{abstract}

El Survey tiene como objetivo principal suministrar a los profesionales de la Numismática un comentario crítico de las publicaciones más recientes. Dicho comentario no es exhaustivo pero si recoge los trabajos más destacados de cada una de las secciones, mostrando además las tendencias generales del período de cobertura. El público al que va dirigido el Survey trasciende las barreras del mundo de la investigación numismática, por lo que sus articulos son una herramienta útil y accesible también para los historiadores, arqueólogos y coleccionistas.

Más información:

www.man.es/cin/survey/survey.htm

\section{Carmen Alfaro}

Coordinadora General del XIII C.I.N.

\section{La Comisión Europea lanza un portal europeo para la Movilidad Profesional}

Desde el pasado mes de septiembre se encuentra abierto el Portal Europeo para la Movilidad Profesional, que tiene como objetivo ofrecer un modo fácil de acceder a la información necesaria para las personas que prevén trasladarse por motivos de carrera o de formación. Además de facilitar información sobre los puestos de trabajo vacantes en el EEE y de ofrecer a los solicitantes de empleo la posibilidad de publicar su currículum vitae en línea, el portal incluirá información sobre las condiciones de vida y de trabajo, las evoluciones del mercado laboral (déficits o excedentes de empleo) y las oportunidades de educación y formación (a través del sitio PLOTEUS, de cuyo funcionamiento se ocupa la Dirección General de Educación y Cultura de la Comisión Europea).

Los profesionales de la cultura y del patrimonio pueden ya acceder a este portal visitando la dirección:

http://europa.eu.int/eures/index.jsp 